\title{
Benchmarking as a Strategic Tool for Achieving Excellence in Higher Education in Jordan
}

\author{
Dr. Sami Al-kharabsheh \\ Al-Isra Private University \\ Amman, Jordan
}

\begin{abstract}
This paper examined the strategic importance of benchmarking as a tool for achieving excellence in higher education in Jordan. Talal Abu-Ghazaleh University College for Innovation (TAGUCI) tried to use The University of Harvard as a benchmark for all its activities. TAGUCI is intended to be The Harvard of the Middle East. The excellence model "The European Foundation for Quality Management (EFQM)" was identified and implemented for increasing the performance of the College. Therefore, the aim of this article is to examine the strategic importance of benchmarking as a tool for implementing business excellence models and therefore achieving excellence.
\end{abstract}

Keywords: Benchmarking, Strategy, Tool, Excellence, Process, Competitive, EFQM, Environment.

\section{Introduction}

Talal Abu-Ghazaleh University College for Innovation (TAGUCI) is a newly established University. We heard from many sources that this university is created to be The Harvard of the Middle East. The university is using benchmarking as a strategic tool for achieving excellence. In today's turbulent business conditions, organizations are striving to identify tools and techniques that will enable them not only to survive but to gain competitive advantage as well. Benchmarking, according to Dattakumar and Jagadeesh (2003) is one such technique that has become popular in the recent times.

Technological developments of the last twenty-five years enabled organizations to become capable of knowing the performance levels of best-in-class organizations such as The University of Harvard and as a result benchmarking became an excellent tool to be used by TAGUCI. Theological process for identifying and implementing better or best practices, known as benchmarking, is to use business excellence models, such as the European Foundation for Quality Management (EFQM). In fact, Ministries of Higher Education in the Arab World, in an effort to improve universities' performance, are setting indicators to measure performance and benchmarking might be used to respond to these indicators and to be considered asa reference criterion and a seal of efficient and effective university management and operation (Anninos, 2007).

\section{Objectives of Study:}

The main objectives of the study include:

*Discovering the meaning of Benchmarking.

*Bringing external focus to internal activities, functions and operations.

*Helping organizations to understand how industry leaders do things.

*Identify what an organization has to change to climb the ladder of quality.

*Showing an organization what is possible to be done and what other institutions have already done.

*Motivating individuals toward achievable goals and strategies that drive their efforts.

*Find the secrets of success and then adapting and improving them for their own application.

\section{Significance:}

The basic philosophy of benchmarking, according to EFQM, is to: know what one wants to improve, identify the 'Good Practices' in those areas, learn from the 'good / best practices', adapt the key insights and incorporate learning into one's own process. In summary, benchmarking to TAGUCI is a way to adopt, adapt and improve good practices.

\section{Research Problems:}

There are 27 Public \& Private Universities in Jordan, 11 public and 16 private. All claim they are the best, although there is a lot of criticism from their own existing or graduated student. Some of them are trying their best to have a good image by adopting new ways and techniques of attracting and educating students, while others are still using the old methods in every aspect and they are shrinking and dying slowly. This paper would give an idea of how and what to use to lift up universities in Jordan. 


\section{Literature Review}

\section{What is Benchmarking?}

Bismarck, first Chancellor of Germany, when told that a wise man learns from experience he replied: "No, a fool learns from experience. A wise man learns from the experience of others." Benchmarking is a positive, proactive process to change operations in a structured fashion to achieve superior performance (Vermeulen, 2003).

Although the use of comparative data has been used for years in some industries, including higher education, benchmarking, as defined today, was developed in the early1980s at the Xerox Corporation in response to increased competition and a rapidly declining market (Camp 1989). Benchmarking is an ongoing, systematic process for measuring and comparing the work processes of one organization.

The American Productivity \& Quality Centre defined benchmarking as “........ the process of continuously comparing and measuring against other organizations anywhere in the world to gain information on philosophies, policies, practices, and measures which will help an organization to take action in improving its performance".The benchmarking concept is understood by some people to be an act of imitating or copying from others. However, in reality, benchmarking proves to be a concept that helps in innovation rather than imitation, The Japanese word dantotsu ("striving to be the best of the best") captures the essence of benchmarking.

The European Benchmarking Code of Practice suggests that benchmarking is simply about making comparisons with other organizations and then learning the lessons that these comparisons throw up.

\section{What is Benchmarking in Education?}

How do we know if students are learning the right things at the right times? Is there even such a thing? Should high achievers set the standard for education? These are the main questions surrounding the practice of benchmarking in education. Benchmarking in education occurs when measurable standards are set for learning. For example, benchmarks might be set for the concepts that must be mastered in each step. They might also be used to see where a particular student, class, or even university ranks in comparison to others.

Now that we understand what benchmarking is, let us look at the reasons for using it.

\section{Why Benchmark?}

Richard is a third year student. His family is moving from New Jersey toNebraska and he will be transferring to a new University. Since states vary greatly in terms of education, how will the new University know where Richard is in terms of academic aptitude? Benchmarking may provide the answer. For example, if Richard'sNew Jersey University is able to share the academic benchmarks that Richard has achieved thus far in third year, it might help the new University place him in the correct program. Therefore, assessment is one reason to use benchmarking. This assessment is not limited to assisting with placement. For example, educators can use benchmarking to improve performance among specific students or even among students at large in at-risk schools and districts. Let us say we have a highperforming school in a certain district in Illinois. Benchmarking may help other schools and districts understand and replicate the practices used in that high-performing Illinois district. In other words, schools can use benchmarking to set standards for best practices in learning and achievement. Stated more simply, benchmarking can raise standards in education by creating a model for excellence and achievement. This model can then be duplicated by others.

\section{Talal Abu-Ghazaleh University College for Innovation (TAGUCI):}

The University College was established in 2018 as an independent University College accredited by the Ministry of Higher Education in Jordan. TAGUCI's programs have been developed, with the advancement in communication and information technology in mind, by the most respected and renowned figures in academia. All programs have been designed to bolster the advancement of technical knowledge with practical real-world applications and through the Case Study approach where appropriate. TAGUCI is the only major institution in the Arab world specializedin teaching applied information technology. The academic programs are supplemented by internships in the Talal Abu-Ghazaleh Organization that practices all the disciplines taught in the University College.

TAGUCI's aim is to prepare students for leadership positions in their specialized fields. It is committed to always develop new programs that help its students meet the demands of the ever-changing global economy. To help achieve its goal of encouraging innovation, TAGUCI is offering student who develop an innovative project that is patentable a grant that cover the cost of their tuition once over. Furthermore, Abu Ghazaleh Intellectual Property (AGIP), the largest Intellectual Property Company in the world, will assist in registering their patent for them. 
(TAGUCI) is offering the potential business leaders an innovative MBA program. Its MBA program with its specialized areas of concentration is unique to our part of the world and has been designed by internationally renowned academicians to meet the highest international standards. Graduates of its program will be equipped with the latest business technologies to meet and to overcome the challenges of the ever-changing business world. Its core curriculum is designed to educate and prepare students with the skills needed to provide leadership to organizations competing in a world increasingly characterized by diversity in the workplace, rapid technological change, and a fiercely competitive global marketplace.

\section{Benchmarking in Higher Education:}

Through the systematic and collaborative comparison of performance with its competitors, Xerox's was the first to adopt benchmarking, and its aim was to evaluate itself, to identify its strengths and weaknesses and adapt to constantly changing market conditions.

Due to its reliance on hard data and research methodology, benchmarking is especially suited for institutions of higher education in which these types of studies are very familiar to faculty and administrators. Practitioners at colleges and universities have found that benchmarking helps overcome resistance to change, provides a structure for external evaluation, and creates new networks of communication between schools where valuable information and experiences can be shared (Alstete, 2008).

Benchmarking, as a process for self-evaluation, was adapted to higher education in North America in the early 1990s, and followed rapidly by Australia and more recently with the UK and continental Europe (Jackson, 2001).

According to the EU-funded project "Benchmarking in European Higher Education", there are ten good reasons to use benchmarking as a management tool. Benchmarking strengthens an institution's ability to successfully: [1] self-assess the institution; [2] better understand the processes which support strategy formulation and implementation in increasingly competitive environments; [3] measure and compare to the competition, i.e. how well are other HEIs in the sector performing, which HEIs are doing better and why; [4] discover new ideas, looking out strategically; [5] learn from others how to improve; [6] obtain data to support decision-making with new strategic developments; [7] set targets for improvement of processes and approaches in order to increase performance; [8] respond to national performance indicators and benchmarks; and [9] set new standards for the sector in the context of higher education reforms. Benchmarking, as it has come to be defined, was an inevitable outcome of the growth of the quality movement, and is considered one of the most powerful tools of TQM and therefore a powerful tool for achieving excellence.

\section{Excellence and Higher Education:}

In the global market of higher education, there are clearly competitive advantages in establishing and maintaining a reputation for providing good quality education, high academic standards, and world-class research output. Excellence comes as the result of achieving higher and higher quality levels. There is no final frontier of excellence. Consequently, excellence could be defined as quality, within quality, for quality (Anninos, 2007). According to the business excellence models, Quality in teaching and learning, in research, in external engagement, in management and infrastructure should be examined and taken into consideration in every attempt to understand and to strive for excellence. Excellence means exceptional performance in areas such as leadership, strategic planning, studentstakeholder and market focus, measurement-analysis and knowledge management, workforce focus, process management and results (Anninos, 2007).

The EFQM Excellence Model is wholly appropriate and beneficial within TAGUCI context, leading to the development of enhanced management practices across both academic and administrative areas. It is clear, however, from the research undertaken by Sheffield Hallam University (2003b), that the Excellence Model is a catalyst for change - providing a framework through which improvement and changes in current practice can be analyzed, prioritized and understood.

\section{Business Excellence and the Role of Benchmarking:}

The EFQM Excellence Model has been developed using input from over 1000 individuals and organizations from across Europe, and has benefited from benchmarking with the United States National Malcolm Baldrige Award scheme, the Japanese Deming Prize and quality management frameworks from South Africa and Australasia. (Shefield Hallam University, 2003b). 
The EFQM Excellence Model “is a practical tool to help organizations establish an appropriate management system by measuring where they are on the path towards Excellence, helping them to understand the gaps, and then stimulating solutions".

The EFQM Excellence Model has been recognized by Sheffield Hallam University (2003b) that the Model provides a number of key benefits, which have been proven to be of significant value.

- It offers a holistic approach

- It provides a process of self-assessment against a non-prescriptive set of criteria

- The assessment process is based on factual evidence that could be embedded into the organization.

- It provides a balanced set of results indicators, not just financial, that focus on the need of the customer, the people in the organization, the local community and other elements of society, the regulatory bodies and the funding providers.

- It provides a framework through which the kernel of the organization's issues could be surfaced, investigated and improved - continually.

- It offers benchmarking opportunities with others within and outside the sector, providing a common language to share good practice and develop both individual and organizational learning

The EFQM Excellence Model provides a common framework and language that can be used to compare performance in all areas, or specific areas against others who are using the same assessment framework. It allows organizations to focus on specific areas for improvement, and learn from others who have had similar learning experiences in the past. It also enables organizations to assess how well they are actually doing in comparison to others, and whether they are actually the 'best-in-class' in a specific area, and could therefore help others (Steed, 2002).

The EFQM Excellence Model provides the framework for analysis, with benchmarking allowing internal and external comparison to promote learning and continuous improvement. There is no final score, or ceiling of achievement, but a progression that needs to be checked and measured through the self-assessment and benchmarking processes (Steed, 2002). Therefore, benchmarking is considered as an important part of the journey towards Excellence.

EFQM (2009) describes benchmarking as the art of opening one's mind to what has made other organizations successful, combined with the ability to creatively translate such insight into successful implementation and improved results. For organizations wanting to achieve Excellence, the biggest challenge can be knowing where and how to start. Organizations, around the world, seeking to reach world class levels of profitability and growth have found that the solution lies in comparing their processes and performance with that of other organizations. They have achieved substantial results by making significant improvement based on learning from Benchmarking projects.

Benchmarking is a tried and tested process that can significantly enable organizational learning and enhance organizational performance (Sheffield Hallam University, 2003a). There are numerous approaches to benchmarking. The English Universities Benchmarking Club has used the following process to underpin their benchmarking activity: Plan, Collect, Analyze, Adapt, and Review. Longbottom (2000) has identified four key stages of benchmarking process, namely planning, analysis, implementation and review. Karlöf and Östblom also describe a five-stage process for benchmarking as follows:

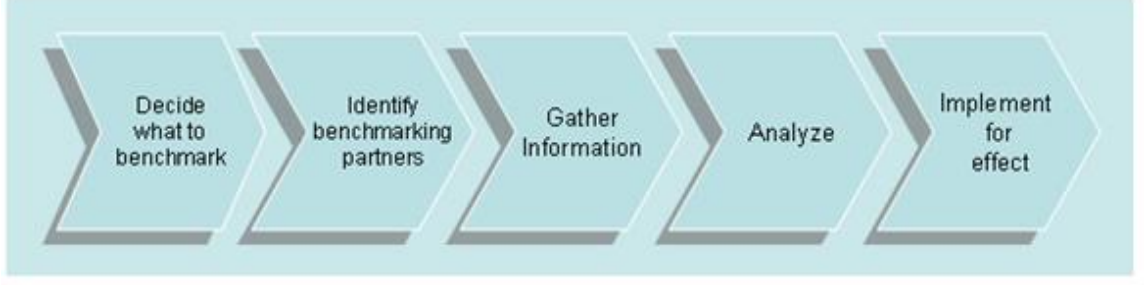

Fig1: The five stages of benchmarking (Karlöf and Östblom, 1995)

Benchmarking is not simply about performance measures. At its most effective, it becomes a core business strategy and for successful implementation, senior management commitment is a prerequisite.

As discussed earlier, the Excellence Models like EFQM and Malcolm Baldrige provide a very effective route into benchmarking. They encourage benchmarking against measures of performance but also stimulate the search for good and/or best practice. Benchmarking has confirmed the importance and potential of a strategic approach to business excellence and is therefore being adopted by universities in search of excellence. There are many examples where the EFQM Excellence Model or the Malcolm Baldrige Award has beenapplied successfully in Higher Education. Actually, 
there have been many award winners and finalists of the European Quality Award (EQA) from the Higher Education sector. The Faculty of Engineering of Marmara University was EQA finalist in 2000, while the City Technology Collegewas EQA finalist in 2001. St Mary's College Northern Ireland was EQA award winner in 2001 and Colegio Ursulinas in Vitoria was a prize winner in 2004. In the United States the equivalent business excellence model, the Malcolm Baldrige Award, has been adapted for use in many HEIs and as a result one university (the University of Wisconsin Stout) has won the Baldrige Prize in 2001. It is important to note that the excellence models have been used successfully by secondary education institutions in both Europe and US.

Jackson (2001) provides an overview of the concept and methodology and provides examples of the ways in which benchmarking is being used, including the Commonwealth Higher Education Management Service (CHEMS) benchmarking approach which is based on the principles and operating framework of the EFQM Excellence Model.

\section{Research Methods}

When the EFQM Excellence model is used to assess the performance of an organization or HEI a specific score is determined. The assessment team provides a feedback report identifying areas for further improvement, together with a scoring profile, at criteria level. This profile can be compared against other profiles and might then lead to benchmarking against organizations that had demonstrated excellence at criterion parts level. By contacting such organizations it is possible to identify what specific approaches might have led to excellence in particular criterion area(s).

Therefore, a HEI's scoring profile can be compared against the scoring profiles of other HEIs in an effort to identify per criterion level the HEI that demonstrate excellent performance. For example, as shown in figure2, HEI 4 seems to have reached better performance levels in the criteria of leadership, policy \& strategy, processes, customer results, people results and key performance results. Similarly, HEI 5 seems to have reached better performance levels in the criteria of people, partnerships \&resources, and society results. In conclusion, by focusing and studying the performance of HEI 4 and HEI 5 one can identify, understand and adapt the outstanding practices from these two HEIs to help improve performance.

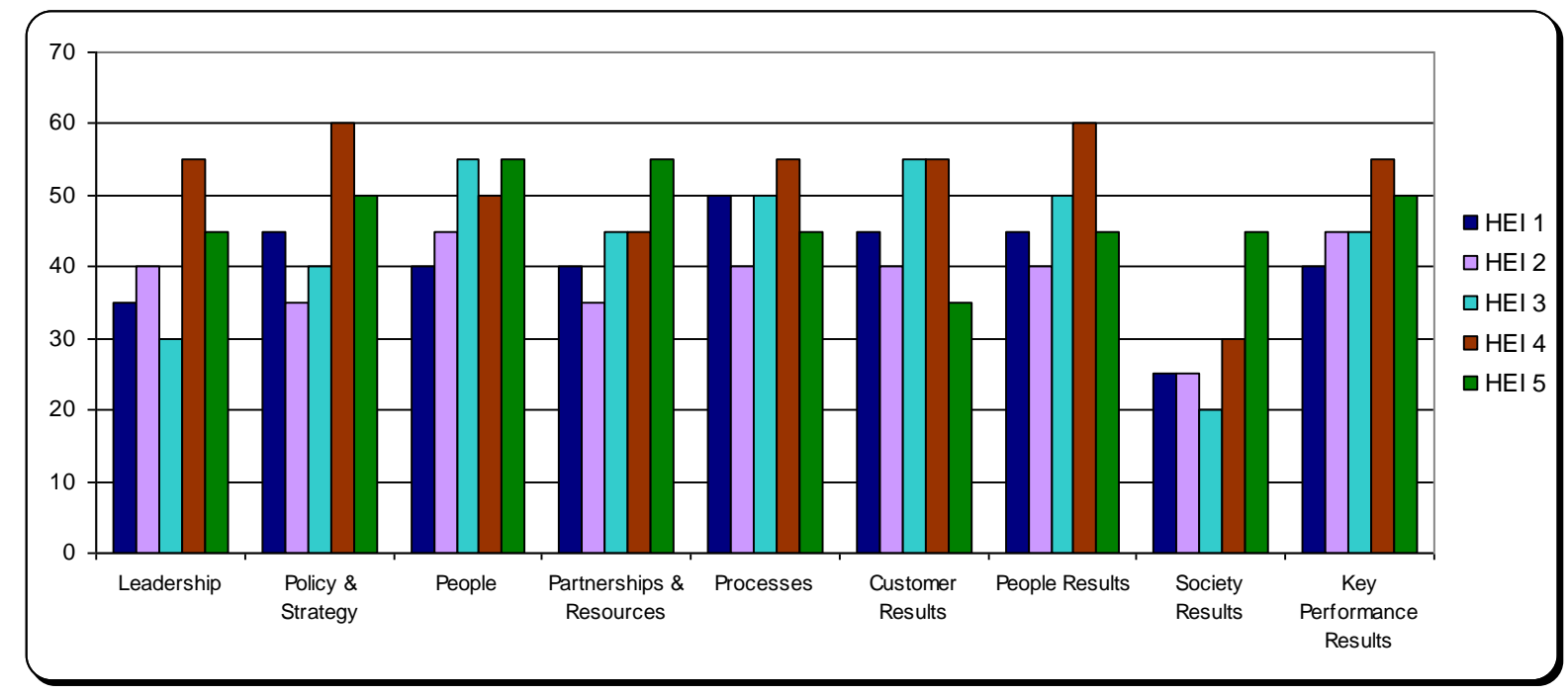

Fig2: Benchmarking using the EFQM scoring profile

Whilst the outcomes and scores from self-assessments can remain confidential, many organizations are able to share the learning, methodology, process improvements and pitfalls with others, without contravening commercial confidence. The publication of reports and scores is not mandatory, but many award winning organizations publish summary documents of their award entries, with changes or omissions of sensitive data. This fosters a culture of learning and sharing within and between sectors, which again is based on the understanding and sharing of a common language and assessment framework (Steed, 2002).

A number of sources of information can help organizations with their benchmarking efforts. These cover the spectrum from non-profit associations to for-profit organizations that sell information. In addition, there are consulting companies with expertise and databases covering all aspects of benchmarking. Excellent sources of information for benchmarking are professional institutions that can direct organizations to best-in-class practices, provide contacts, and 
offer valuable advice. EFQM's Good Practice Database contains the best-in-class results that have been achieved by Winners and Finalists of the EFQM Excellence Award over the past 5 years, covering the areas of customer results, people results, society results and key performance results. On the other hand, Baldrige Award winners in the US are committed to share information with other US companies, and they hold periodic seminars for this purpose. A wide range of benchmarking information is available on the Internet, like the Greek Benchmarking Centre that provides comparative evaluation for enterprises and institutions through on-line applications developed by the Centre, or the Australian Universities Quality Agency (AUQA) Good Practice Database and the relevant comprehensive guide to Higher Education benchmarking.

\section{Sources of Information:}

The current study used two sources to get data, secondary and primary sources. In the secondary source, the data was collected from various available sources that include published articles and books, doctoral dissertations, previous studies and website materials in order to form the theoretical framework of the study. The primary source was gathered from the official records of the Harvard and the questionnaire that was designed and developed to reflect the study objectives and statements.

\section{Conclusion:}

Benchmarking can provide solutions in finding out how to improve activities and to provide benchmark comparators in the development of comprehensive measurement frameworks. Undertaken creatively it can provide a powerful tool for achieving excellence (Shefield Hallam University, 2003a). There is no doubt that significant benchmarking trends can be pursued in every industry sector, including the higher education. In the near future, managing benchmarking and best practice sharing programs in an organization of any size will be an imperative, while software-based benchmarking will become a widely accepted practice for conducting benchmarking electronically.

\section{Recommendations:}

The challenge for higher education will be to develop benchmarking in a way that will help people learn about and improve their own practice while improving the overall capacity of the higher education system to develop, improve and regulate itself (Jackson, 2001). Best practice benchmarking will be seen as a strategic need for organizations and HEIs. Benchmarking is a competitive strength when practiced, and can be a fatal weakness when overlooked.

\section{Future Research:}

Benchmarking is not something to be bought, copied or imitated fully. It is something to be looked at, to see the differences, to check the abilities and to develop strategies. Today, benchmarking is used by a number of universities as a strategy, since the competition amongst them is fierce and they attempt to create a competitive advantage. This strategic approach is not only used for survival but for being distinct and different from the competition. Benchmarking is an option that every organization and institution has; but as Dr. Deming said, "Survival is not compulsory". Future research is highly required to find means and ways to adopt benchmarking.

\section{References:}

American Productivity and Quality Centre, The Benchmarking Code of Conduct - viewed 28 April 2020.

Australasian Council on Open Distance and E-Learning 2014, ACODE - Inter-Institutional Benchmarking Summit viewed 20May 2020.

Australian Universities Quality Agency (AUQA), Good Practice Guide - viewed 5June 2020

Alstete, J. (2008), Benchmarking in Higher Education: Adapting Best Practices to Improve Quality, ASHE-ERIC Higher Education Report series 95-5.

Camp, R.C. (1989), Benchmarking: The Search for Industry Best Practices That Lead to Superior Performance. Milwaukee, WI: ASQC Quality Press.

Commonwealth Department of Education, Science and Training, Best Practice Processes for University Research Commercialization Final Report - viewed 10 April 2020

Dattakumar R. and Jagadeesh R. (2003), “A review of literature on benchmarking”, Benchmarking: An International Journal, 10(3), 176-209

EFQM (2009), European Foundation for Quality Management at http://www.efqm.org/Default.aspx?tabid=140

ESMU, (2008), Benchmarking in European Higher Education - Findings of a two-year EU -funded project, European Centre for Strategic Management of Universities.

Higher Education Standards Framework (Threshold Standards) (2015), Subsection 58(1) of the Tertiary Education Quality and Standards Agency Act 2011 (TEQSA Act 2011) (2015). 
Guide to The Association of Commonwealth Universities (ACU), United Kingdom, Measures benchmarking tool viewed 17 April 2020

Jackson, N. (2001), "Benchmarking in UK Higher Education: an overview", Quality Assurance in Education, Vol. 9, Number 4, pp.218-235.

Karlöf, B., Östblom, S. (1995), Benchmarking, A signpost to Excellence in Quality and Productivity (John Wiley and Sons).

Kempner, D.E. (1993), The Pilot Years: The Growth of the NACUBO Benchmarking Project. NACUBO Business OfficerLongbottom, D. (2000), "Benchmarking in the UK: an empirical study of practitioners and academics", Benchmarking: An International Journal, Vol. 7, No. 2, pp.98-117.

Shefield Hallam University, (2003a), Benchmarking methods and experiences, Centre for Integral Excellence publication.

Shefield Hallam University, (2003b), Embracing excellence in education - A summary of the learning gained from applying the EFQM Excellence Model ${ }^{\circledR}$ in Further and Higher Education, Centre for Integral Excellence publication.

Shefield Hallam University, (2003c), Application of theEFQM Excellence Model®in a College of Further Education, Centre for Integral Excellence publication.

Steed Carol (2002), "Excellence in Higher Education - Evaluating the implementation of the EFQM Excellence Model in Higher Education in the UK", BeiträgezurHochschulforschung, Heft 1, 24. Jahrgang, 2002, athttp://www.ihf.bayern.de/dateien/beitraege/Beitr_Hochschulf_1_2002.pdf

Tertiary Education Quality and Standards Agency (2016), Guidance note: External referencing (including benchmarking). Retrieved from http://www.teqsa.gov.au/sites/default/files/BenchmarkingGNFinal_0.

Thompson I. and Cox A. (1997), "Don't imitate, innovate", Supply Management, 40-3.

United Nations Educational, Scientific and Cultural Organization (UNESDOC), Benchmarking in higher education: a study conducted by the Commonwealth Education Management Service - viewed 23May 2018

Zairi M (1996), Benchmarking for Best Practice: Continuous Learning through Sustainable Innovation, Butterworth Heinemann. 